\title{
A Study on Noise Reduction of Gear Pumps of Wheel Loaders Based on the ICA Model
}

\author{
Panling Huang ${ }^{1,2}$, Liang $X u^{1,2}$, Chuan Luo ${ }^{1,2}$, Jianchuan Zhang ${ }^{1,2, *}$, Feng Chi ${ }^{3}$, Qi Zhang ${ }^{3}$ and \\ Jun Zhou ${ }^{1,2}$ \\ 1 School of Mechanical Engineering, Shandong University, Jinan 250061, China; hfpl@sdu.edu.cn (P.H.); \\ x19931120@163.com (L.X.); luoc_oo@163.com (C.L.); zhoujun@sdu.edu.cn (J.Z.) \\ 2 Key Laboratory of High Efficiency and Clean Mechanical Manufacture, Shandong University, \\ Ministry of Education, Jinan 250061, China \\ 3 Shandong Lingong Construction Machinery Co., Ltd., Linyi 276023, China; feng.chi@sdlg.com.cn (F.C.); \\ qi.zhang@sdlg.com.cn (Q.Z.) \\ * Correspondence: zhangjianchuan@sdu.edu.cn
}

Received: 15 January 2019; Accepted: 9 March 2019; Published: 19 March 2019

\begin{abstract}
In order to reduce the noise level of wheel loaders caused by gear pumps and realize environmentally sustainable development, the noise generation mechanism of a gear pump was studied, and the influence of flow pulsation and gear impact on noise was analyzed. In order to reduce the interference of other noise sources on the noise level of the gear pump, a noise test rig was established. The mixed noise signals obtained from the rig test were separated using the ICA model. The ICA model includes the following algorithms: The fast Fourier transform (FFT), independent component analysis (ICA) and inverse fast Fourier transform (IFFT). Some theories about the influence of the teeth number and teeth profile on noise were analyzed by theory and simulation. A noise reduction strategy was proposed by increasing the teeth numbers and modifying the teeth profile of the gear pump. The tests results showed that the noise values of the external and the driver's ear of the wheel loader were reduced to 1 and $2.2 \mathrm{~dB}(\mathrm{~A})$, respectively. This proves the effectiveness of the optimization scheme of gear pump noise reduction.
\end{abstract}

Keywords: gear pump noise; construction machinery; noise reduction and ICA

\section{Introduction}

After entering the 21st century, in order to achieve environmental sustainability, environmental protection technology and information technology of construction machinery are put forward, which makes construction machinery enter a new stage of development. European and American markets have put forward stricter requirements for noise control of construction machinery products. Gear pumps are the units that perform the energy conversion from the mechanical energy to the pressure energy of oil. They are extensively used in construction machineries due to their advantages such as small size, light weight, insensitivity to oil pollution, reliable operation, good performance, and low production costs [1,2]. However, their significant disadvantage is relatively high noise emission [3]. Construction noise can cause a series of detrimental health effects on human beings, such as noise-induced hearing loss [4], arrhythmia, dyslipidemia, cancer, thyroid gland disorders and psychic disorders, and so on [5]. Therefore, the construction noise level must be reduced in order to develop environmental sustainability and improve the market competitiveness of construction machinery.

The causes of noise generation are as follows [6]: (1) Pressure shock and cavitation arising from the trapped volume between meshing teeth; (2) the noise caused by some manufacturing errors of gears during gear meshing; (3) flow pulsation and pressure pulsation caused by the volume change of the suction chamber and discharge chamber. 
In addition to sustainable development needs, reducing noise levels can also increase the life and reliability of equipment. At present, many scholars are studying the noise generation mechanism and noise reduction strategy of gear pump. Many studies have shown that pressure and flow pulsations are the main causes of noise generation, not the noise radiation of the pump itself. The intrinsic noise of gear pumps mainly depends on the vibrations and dynamic load on the gears. These dynamic loads are transmitted through the bearings in pump housing and generate noise [7]. Mucchi [8] thought that the noise levels are the consequence of the dynamic forces within the gear pump system, related with the flow and pressure ripple as well as the variable meshing stiffness and gear errors. Zhao [9] believed that in the design of the involute tooth profile of the traditional external gear pump, the inherent cause of significant flow inhomogeneity leads to undesired noise emissions and mechanical vibrations for involute teeth design of the traditional external gear pump. Therefore, continuous-contact helical gear pumps were proposed and successfully commercialized to replace the traditional gear pumps in the recent past. However, the high manufacturing cost of helical gear restricts its popularization and application in construction machinery. Some scholars have also carried out research work on noise reduction of piston pumps [10,11].

Independent component analysis (ICA) is a technique recently used in data analysis and signal processing. It is used in many fields: Blind source separation [12], image restoration of blurred images [13], brain magnetic resonance image analysis [14], telecommunications [15], financial data analysis [16], facial identification [17], and so on. In this paper, ICA methods were used in the signal processing of gear pumps. The purpose of using ICA signal separation is to verify the effectiveness of gear pumps before and after optimization.

In order to avoid the deviation of gear pump noise caused by other components in the whole machine noise test, the following two effective measures were adopted in this paper: The noise test rig of the gear pump was set up to avoid the influence of other noise sources, and the noise signals of gear pumps were separated by using the ICA model. The noise generation mechanism of the gear pump was analyzed by combining theoretical analysis with the finite element analysis (FEA) method. A noise reduction strategy of gear pumps was put forward based on the above analysis. Finally, noise tests were carried out to verify the effectiveness of noise reduction.

\section{Research Foundation and Content}

Figure 1 shows the main research contents of this paper. In early research, the values of the external radiation noise and the driver's position noise were obtained by the test of the whole machine noise for the wheel loader. The test and sound pressure calculation of wheel loaders were carried out in accordance with the requirements of national standards GB/T25614-2010 and GB/T25612-2010 of the People's Republic of China. The sound pressure values of the wheel loader are shown in Table 1. Among them, CE (the abbreviation of French, it means EUROPEAN CONFORMITY in English) certification values were obtained according to European $C E$ certification requirements. It can be seen from the table that the measured noise value was greater than the CE certification value, so it is necessary to study the noise reduction of the wheel loader. Through spectrum analysis and the acoustic array noise location method, it was found that the gear pump and the engine were the main noise sources of wheel loaders. Therefore, the next study will be divided into two parts. This paper mainly studies the noise reduction theory of the gear pump. The theory of engine noise reduction will be developed in the next stage.

Table 1. The noise value of the wheel loader.

\begin{tabular}{ccc} 
& Measured Values dB(A) & CE Certification Values dB(A) \\
\hline The driver's position noise & 81.5 & $<80$ \\
The external radiation noise & 110.3 & $\leq 107$ \\
\hline
\end{tabular}




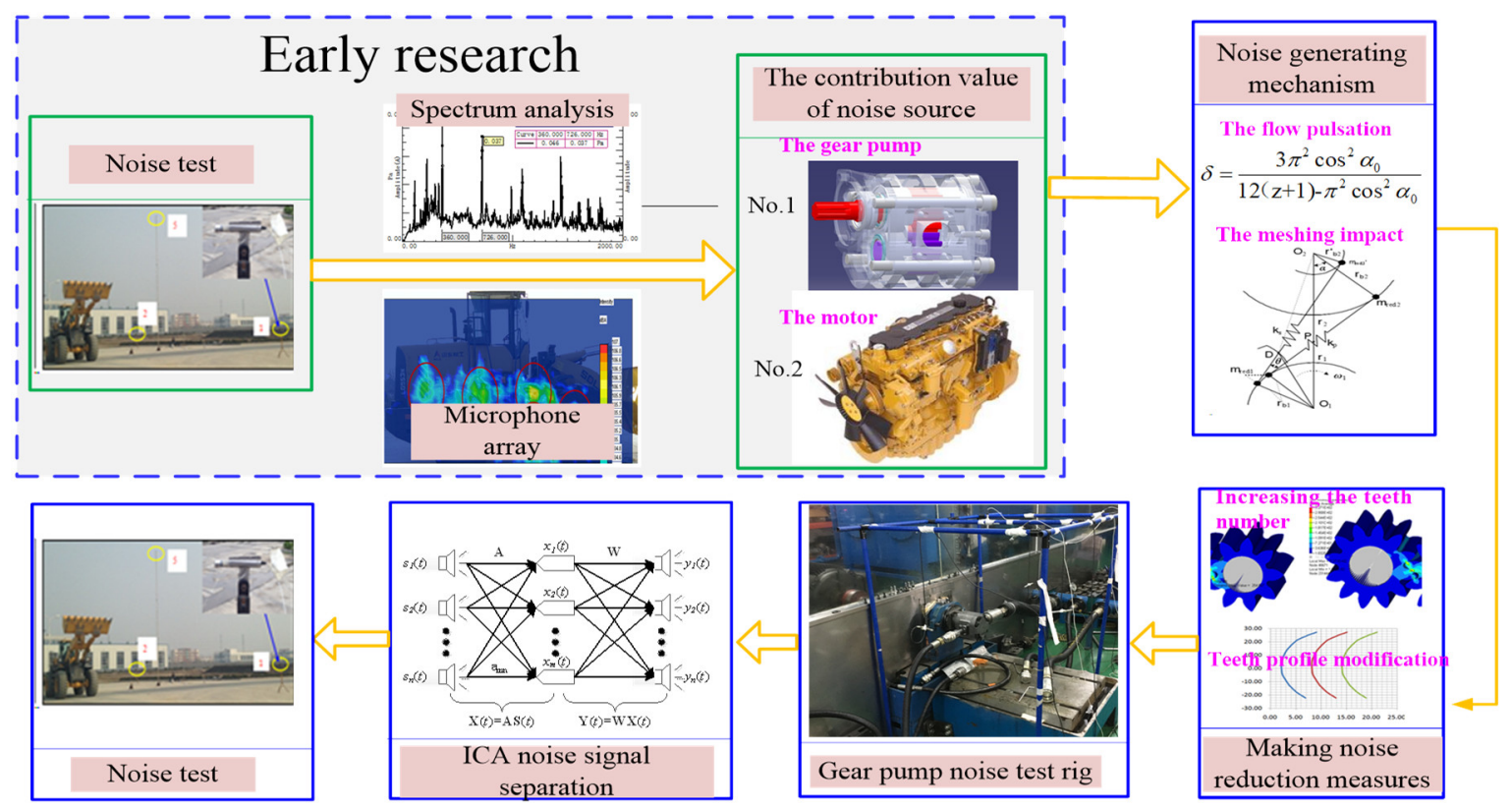

Figure 1. The main research contents.

\section{Methodology}

The gear pump studied is shown in Figure 2. With the meshing transmission between the driving wheel and the driven wheel, the meshing volume between the teeth also changes. When the meshing teeth on the inlet side are separated gradually, the volume of the inlet port increases and the pressure decreases, and the liquid in the suction pipe is sucked into the pump. It is then carried around the sides of the gears by the teeth. Last, the fluid in the pump is delivered to the output port and then into the working oil circuit. Then, new fluid is sucked from the inlet port and discharged with the meshing of the gears. Through these operations, the oil suction and oil discharge of the gear pump in the hydraulic system can be completed, so as to provide power for the hydraulic system.

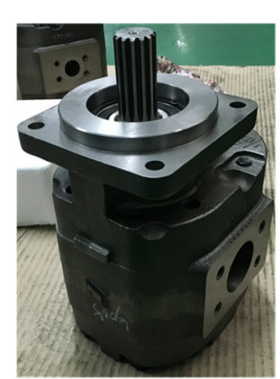

Gear pump

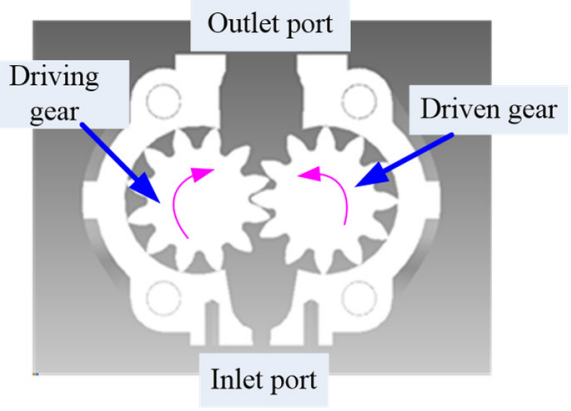

Figure 2. Gear pump structure diagram.

\subsection{The Noise Generation Mechanism of the Gear Pump}

There are many factors that cause the noise generation of gear pumps. However, considering the manufacturing cost, and not changing the volume structure of the gear pump, this paper will mainly consider the influence of flow pulsation and meshing impact on noise generation.

\subsubsection{The Flow Pulsation}

Usually, gear meshing makes a significant contribution to pressure and flow ripples. Ripples are main sources of vibrations, noise, and efficiency loss of gear machineries [18]. The instantaneous flow rate of gear pumps is uneven and varies with time. However, when the hydraulic pump rotates 
continuously, the instantaneous flow varies, according to the same rule. This phenomenon is called the flow pulsation of the gear pump. The flow pulsation of the gear pump determines the performance of the hydraulic system. If the flow pulsation of a gear pump is large, it will not only make the stability and uniformity of the working element worse, but also cause the vibration of the whole hydraulic system and emit a higher decibel noise. Therefore, for noise reduction measures of gear pumps, we should first consider reducing the flow pulsation.

The flow pulsation formula is expressed as follows [19]:

$$
\delta=\frac{Q_{\max }-Q_{\min }}{Q}=\frac{Q_{\max }-Q_{\min }}{i \cdot n \cdot q}
$$

where $Q_{\max }$ and $Q_{\min }$ represent the maximum and minimum instantaneous flow, $Q$ represents the average flow rate of the gear pump, $i$ represents the speed drive ratio between the gear pump and motor, $n$ represents the speed of the motor, and $q$ represents the output volume of the gear pump.

By further calculation, the flow pulsation of the gear pump with side gap meshing is as follows:

$$
\delta=\frac{3 \pi^{2} \cos ^{2} \alpha_{0}}{12(z+1)-\pi^{2} \cos ^{2} \alpha_{0}}
$$

and the flow pulsation of the gear pump without side gap meshing is as follows:

$$
\delta=\frac{3 \pi^{2} \cos ^{2} \alpha_{0}}{48(\mathrm{z}+1)-\pi^{2} \cos ^{2} \alpha_{0}}
$$

where $\alpha_{0}$ represents the pressure angle of the meshing gears and $z$ represents the teeth number of the gears.

From the above formula, it can be seen that increasing the pressure angle and the teeth number of the gear can reduce the pulsating flow.

\subsubsection{The Meshing Impact of Gear Teeth}

Besides the flow pulsation of gear pumps, the meshing impact of gear teeth also produces noise due to the meshing characteristics of gears. As shown in Figure 3, for a pair of gears, the base pitch of the driving gear $(\mathrm{Pb} 1)$ is different from that of the driven gear $(\mathrm{Pb} 2)$ due to the profile error, installation error and bearing deformation during meshing transmission. Different base pitch can cause change of the instantaneous transmission ratio when it enters or exits meshing, which causes vibration and noise.

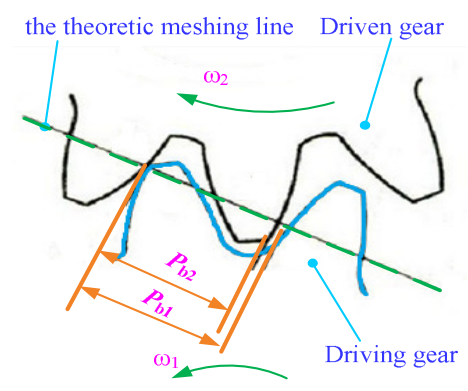

Figure 3. Mechanism of meshing impact.

The noise reduction measures of the gear meshing impact should start with reducing impact energy and making gear meshing more stable. The main noise reduction method in this paper was to improve the gear processing accuracy by profile modification. Drum profile modification is the most widely used method. In most cases, the drum shape under the centrosymmetric condition can effectively compensate for the unbalanced load of gears, except for the excessive skewness or the 
small load. The factors to be considered in drum profile modification include drum shape and drum center position.

Generally, the teeth number of gear pumps is between 6 and 30. In the application of the loader, the requirement of displacement uniformity of gear pumps is not high, but there are certain requirements for installation size of a gear pump and the radial force on the gear to ensure the service life of the bearing and gear pump.

\subsection{The Noise Reduction Strategy}

Noise is emitted from the sound source, radiated to the outside, and then transmitted to the receiver through a certain sound transmission way. According to the mechanism of noise generation, noise can be controlled through three aspects: Noise source, the sound transmission path, and the receiver. So, the following noise reduction strategies can be adopted [20].

\subsubsection{Reducing Noise at the Sound Source}

It is most fundamental and effective to control noise directly at the sound source. The following methods can be used to reduce noise: Developing and selecting low noise equipment, optimizing production and processing technology, selecting the appropriate materials and structures, or improving the machining and assembly precision of parts.

In this paper, noise reduction of the hydraulic gear pump was mainly achieved by increasing the teeth number of the gear pump and modifying the profile of gears. This is a method to reduce the noise of the sound source.

\subsubsection{Control Noise in the Transmission Path}

When the pressure of technical and economic cost exists in noise source control, the transmission path becomes the preferred measure. Usually, in construction machinery, sound insulation, sound absorption, vibration damping, and noise elimination are often adopted to achieve noise control in the transmission path.

In the previous study, some sponges were pasted onto noise sources for noise reduction (as shown in Figure 4). This is a noise control method from the transmission path.

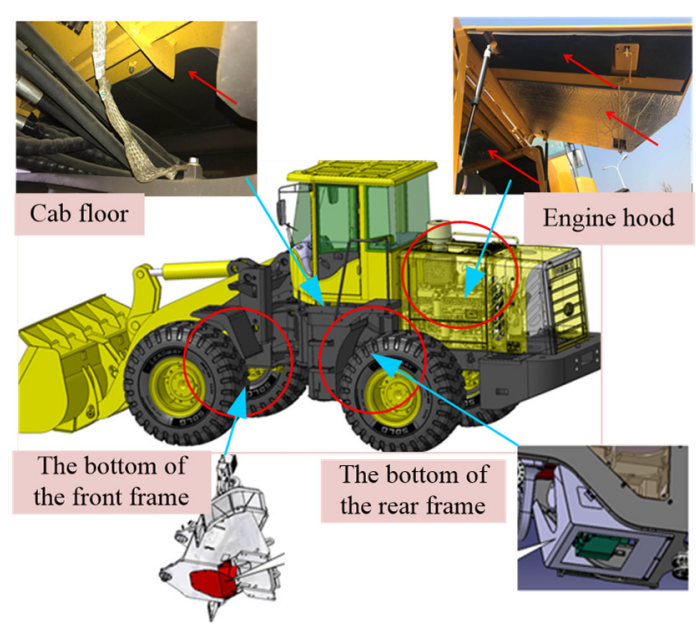

Figure 4. Pasting sponge to reduce noise.

\subsubsection{Control Noise at the Receiver}

Operators can be protected by wearing earplugs, and equipment and instruments can be protected by sound insulation and vibration isolation. However, in engineering machinery, it is difficult for drivers to take corresponding protective measures. 


\subsection{Noise Measurement of the Test Rig}

The measurement and calculation methods refer to the national standard (GB/T 3767-1996), "Acoustics-Determination of sound power levels of noise sources using sound pressure-Engineering method in an essentially free field over a reflecting plane" [21]. Figure 5 shows a schematic diagram of noise measurement of a gear pump. The gear pump is driven by a motor (model: SIEMENS 180kW DC (Siemens, Munich, Bayern, Germany)), and the motor speed is measured by an optical speed sensor (model: PZ-V31P, Keyence, Japan). Noise signals are measured by six acoustic sensors (model: PCB-378B02, GRAS, Denmark). Multi-channel data acquisition instrument (model: scada02, LMS, Belgium) and a Laptop are used to collect and analyze the signals.

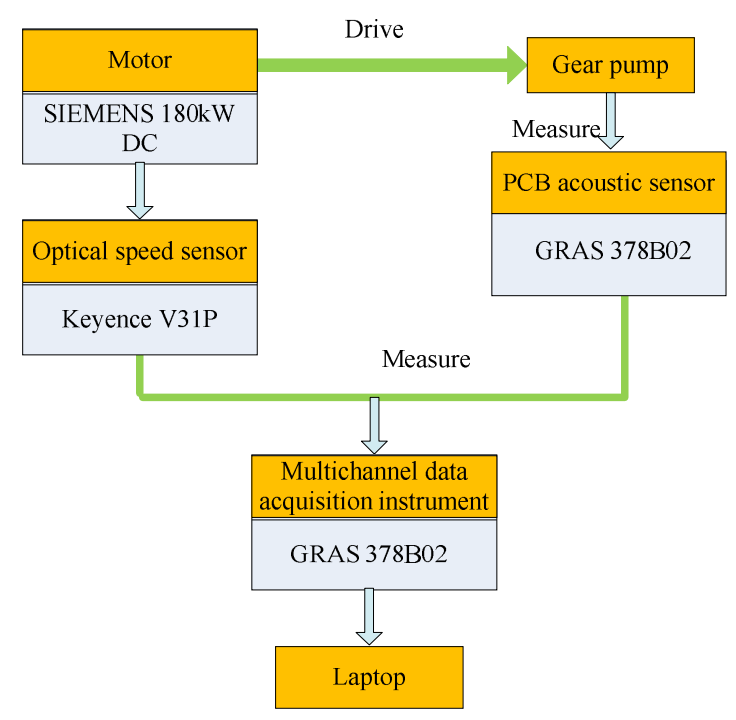

Figure 5. Schematic diagram of noise measurement.

The test rig for noise measurement is shown in Figure 6, where (a) represents the layout of acoustic sensors $(2 \mathrm{a}=0.9 \mathrm{~m}, 2 \mathrm{~b}=1.18 \mathrm{~m}, \mathrm{c}=1.12 \mathrm{~m})$, and $(\mathrm{b})$ represents the test site. In order to reduce the influence of motor noise on gear pump noise, a partition wall is used between the motor and gear pump.

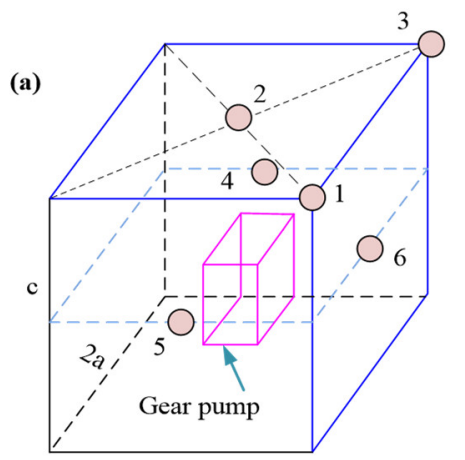

$2 b$

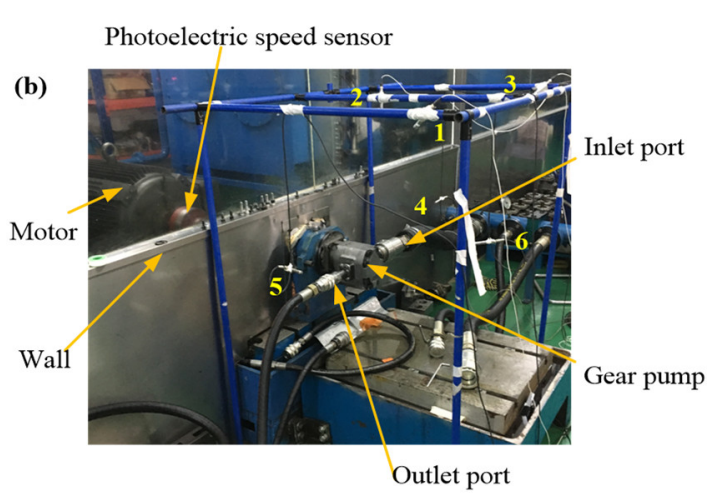

Figure 6. Test rig used for noise measurement. (a) Acoustic sensor layout, (b) test site.

During the test, the motor speed was set to $2200 \mathrm{rpm}$, which is the same as the rated speed of a gear pump when it works normally. At the same time, the relief valve was adjusted to make the normal working pressure $20 \mathrm{MPa}$. Under this pressure, the radiation sound pressure of the test pump was measured. The original normal gear pump was selected in the test. 
By calculating the sound power of the gear pump, it was concluded that the acoustic power of the sampling pump $\left(2200 \mathrm{r} / \mathrm{min}\right.$, working pressure $20 \mathrm{MPa}$, and oil temperature $\left.50^{\circ} \mathrm{C}\right)$ was $100.6 \mathrm{~dB}(\mathrm{~A})$. Adjust the relief valve to normal working pressure of $20 \mathrm{MPa}$.

\subsection{Noise Signal Separation Based on the ICA Model}

In this test, the noise signal obtained includes not only the noise of the gear pump, but also the noise of the motor and other accessories. The ICA algorithm is used to separate the desired noise signal from the mixed noise.

The transmission process of the gear pump is complex, and there is a time delay, a path effect, and reflective reverberation in the propagation process. Therefore, the traditional time domain of the ICA algorithm is not suitable for the separation of noise signals. In order to solve this problem, this paper extended the separation algorithm to the frequency domain.

\subsubsection{The ICA Model}

Suppose there are $n$ unknown independent statistical sources, which are transmitted by unknown channels and eventually accepted by $m$ receivers. Considering the influence of the path delay and reverberation in signal transmission, the received signal of the receiver $\left(x_{i}(t)\right)$ is no longer a simple linear instantaneous mixing but a linear convolution mixing:

$$
x_{i}(t)=\sum_{j=1}^{n} \sum_{p=0}^{P} h_{i j}(p) s_{j}(t-p)
$$

where $h_{i j}$ is the response function between the $j$ th source signal and the $i$ th receiver, $s_{j}(t-p)$, is the delay function of the $j$ th source signal to the $i$ th receiver through different channels. The model is a convolution mixed model expressed as:

$$
X(t)=H(t) * S(t)
$$

where $X(t)=\left[x_{1}(t), x_{2}(t), \ldots x_{\mathrm{m}}(t)\right]^{\mathrm{T}}$ is the mixed matrix obtained by the receivers, $S(t)=\left[S_{1}(t), S_{2}(t)\right.$, $\left.\ldots S_{\mathrm{m}}(t)\right]^{\mathrm{T}}$ is the source signal matrix, and $H(\mathrm{t})$ is the mixture matrix in the time domain.

At present, the ICA algorithm based on the linear instantaneous mixed model is not suitable for convolutional mixing. Therefore, this paper used Fourier transform to transform the convolution mixing problem from the time domain to the frequency domain. The formula is as follows:

$$
X(f)=H(f) S(f)
$$

where $X(f)=\left[x_{1}(f), x_{2}(f), \ldots x_{\mathrm{m}}(f)\right]^{\mathrm{T}}$ is the observed signal matrix in the frequency domain, $H(f)$ is the $m \times n$ hybrid matrix, and $S(f)=\left[s_{1}(f), s_{2}(f), \ldots s_{n}(f)\right]^{\mathrm{T}}$ is the source signal matrix. In the process of signal separation, we need to find a linear separation matrix $W$ to obtain the estimated signal from the source signal. Hence, the separation of ICA can be expressed as:

$$
Y(f)=W X(f)=W[H(f) S(f)]
$$

where $Y(f)$ is the estimation of signal sources in the frequency domain.

The separation process of the mixed signals based on the ICA model is shown in Figure 7.

The specific description is as follows: The mixed signals are collected by a data acquisition instrument and converted into the frequency domain by fast Fourier transform (FFT). The ICA algorithm is used to separate mixed frequency domain signals into various source signals. Fast Fourier inverse transformation (IFFT) is used to transform the frequency domain signals into time domain signals. 


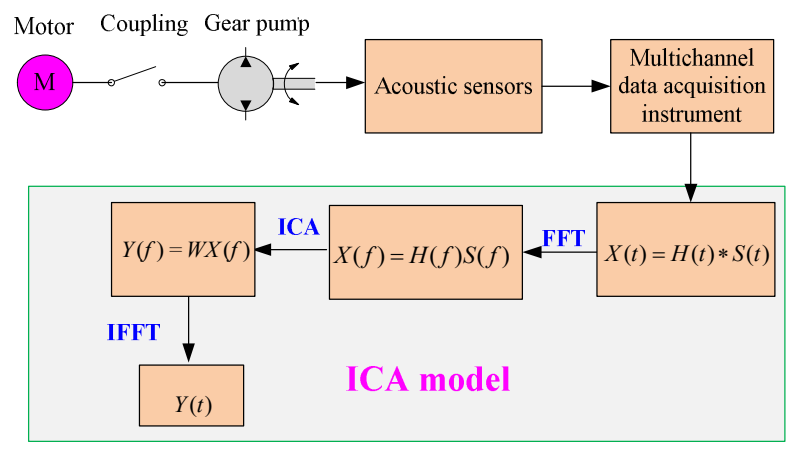

Figure 7. Separation process of the noise source of the gear pump.

\subsubsection{Spectrum Analysis}

The noise data of six measurement points are analyzed by $1 / 3$ octave, the frequency spectrum and the weighted average. Figure 8 shows the average value of the sound pressure spectrum, which provides a theoretical basis for noise source analysis.

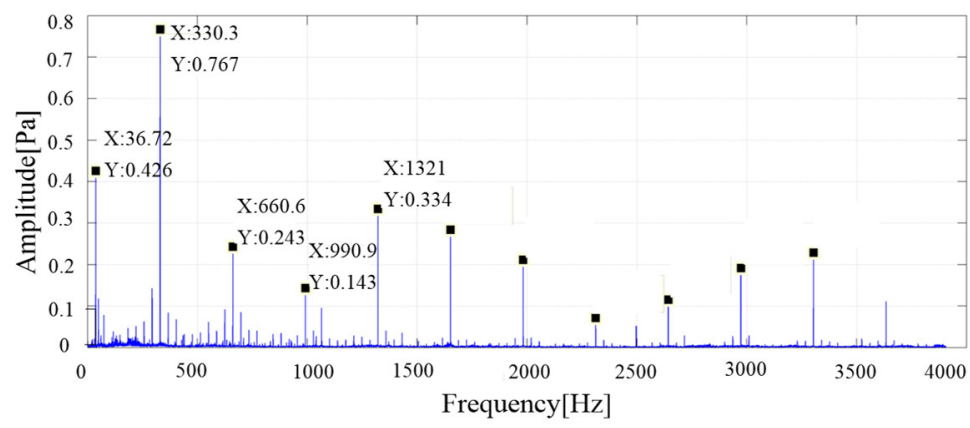

Figure 8. Noise pressure spectrum of the original gear pump test rig.

The maximum peak frequency in the figure is close to $330 \mathrm{~Hz}$, which is consistent with the meshing frequency of the gear pump (calculated according to Formula (8), the teeth number $z$ is 9 ). The second is the larger peak frequency of $36.7 \mathrm{~Hz}$, which is the basic frequency of the motor (calculated according to Formula (9)). Other prominent frequency components are integral multiple frequencies of the fundamental frequency of the gear pump:

$$
f=\frac{n}{60} \cdot z=\frac{2200}{60} \cdot 9=330 \mathrm{~Hz}
$$

where $n$ is the motor speed, and $z$ is the teeth number of the gear pump

$$
f=\frac{n}{60}=\frac{2200}{60}=36.7 \mathrm{~Hz}
$$

\subsubsection{Noise Extraction from the Mixed Noise}

In this paper, the ICA model was used to deal with the noise data of six measurement points. The noise signal of the gear pump was extracted to obtain a more accurate measurement value, and the noise level of the gear pump before and after optimization were compared.

The time-domain signals of six measuring points were processed by fast Fourier transform to obtain frequency-domain signals, and then the frequency-domain signals were pretreated by means processing, whitening, the eigenvalue decomposition method, and so on. It was estimated that there were three independent sources. Figure 9 is the spectrum of three source signals separated by the ICA model. 

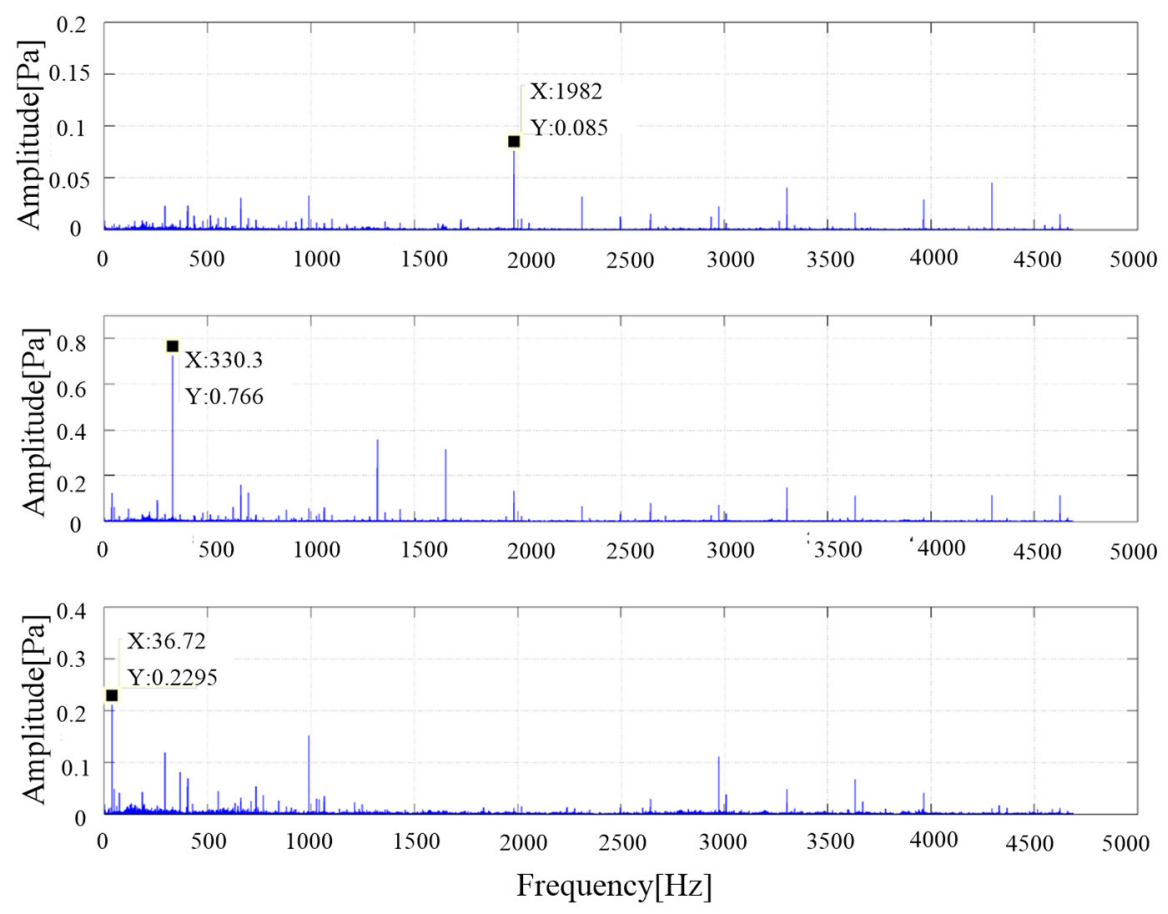

Figure 9. Results of noise separation of the test rig of the original gear pump.

As can be seen from the figure, the main peak frequency of signal 1 was $1982 \mathrm{~Hz}$, and the amplitude was only 0.0852 . The frequencies were mainly concentrated in the middle and high frequency bands. It was estimated that the noise may be caused by accessories such as relief valves. The main peak frequency of signal 2 was $330.3 \mathrm{~Hz}$ (meshing frequency of the gear pump). The amplitude of signal 2 was obviously larger than that of the other two signals, including medium and high frequencies such as $1321 \mathrm{~Hz}(4 \times 330.3$, four order) and $1652(5 \times 330.3$, five order), and so on. Therefore, it can be inferred that the main noise comes from gear pump.

The corresponding frequency of signal 3 was $36.5 \mathrm{~Hz}$, which is consistent with the motor speed, and the amplitude was about 0.23 . Therefore, it can be deduced that the noise comes from motor.

IFFT was used to transform signal 2 in the time domain to get the noise signal of the gear pump. The final sound pressure was $87.6 \mathrm{~dB}(\mathrm{~A})$ by calculation.

\section{Gear Pump Optimization Strategy and Test Verification}

\subsection{Gear Pump Optimization Strategy}

This paper combined the noise generation mechanism of the gear pump and reduced the gear pump noise by increasing the teeth number and improving the tooth profile of the gear pump.

\subsubsection{Increasing the Teeth Number of the Gear Pump}

(1) The flow pulsation

According to Formula (2), the flow pulsation of a gear pump is related to the pressure angle and the teeth number of the gear pump. The teeth number of the original gear pump was 9 , and the pressure angle was $20^{\circ}$. Considering the cost of gear processing and strength, the maximum teeth number was set to 12 in this paper. In accordance with Formula (2), the influence of different teeth numbers on the flow pulsation is shown in Table 2.

It can be seen from the table that the flow pulsation of the 12-tooth was 5.7\% less than that of the original 9-tooth gear pump under the constant volume structure of the gear pump.

(2) The meshing force 
Generally speaking, under the same working conditions, for the same system, the smaller the meshing force, the smaller the impact noise. Therefore, the meshing force between gears is analyzed by using finite element analysis software (Hyperwork). The rigid body element is used to simulate the intermediate shaft body, and the 5 freedom degrees of the rigid element are restrained to release the freedom degree of rotation. The displacement of the gear pump is 166 milliliter per revolution, the motor speed is set to $2200 \mathrm{r} / \mathrm{min}$, and the system pressure of the gear pump is set to $20 \mathrm{MPa}$. Hence, the output torque $M_{t}$ is calculated by Formula (10):

$$
M_{t}=\frac{P q v}{\mu 2 \pi}
$$

where $P$ is the outlet pressure of the gear pump, $q_{v}$ is the displacement of the pump (mL/rev), and $\mu$ is the mechanical efficiency of the pump, set to 0.9 . Therefore, $M_{t}$ calculated by Formula (10) is $587 \mathrm{~N} \cdot \mathrm{m}$.

Under the above conditions, the meshing transmission of the gear pump was simulated by software. Figure 10 shows the input conditions and the simulation results of Mises stresses at different times, where (a) and (b) are the motor speed and output torque loaded on the gear pump, respectively, and (c) and (d) are the Mises stress nephogram of the original 9-tooth and the 12-tooth gear pump corresponding to a certain time.

Table 2. The flow pulsation with different teeth numbers.

\begin{tabular}{cc}
\hline The Teeth Number $z$ & Flow Pulsation Rate $\delta(\%)$ \\
\hline 9 & 23.5 \\
10 & 21.2 \\
11 & 19.3 \\
12 & 17.8 \\
\hline
\end{tabular}

(a)

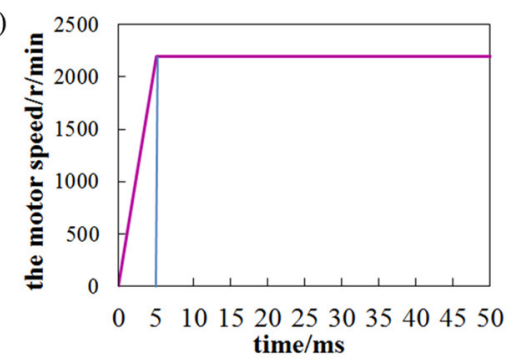

(b)

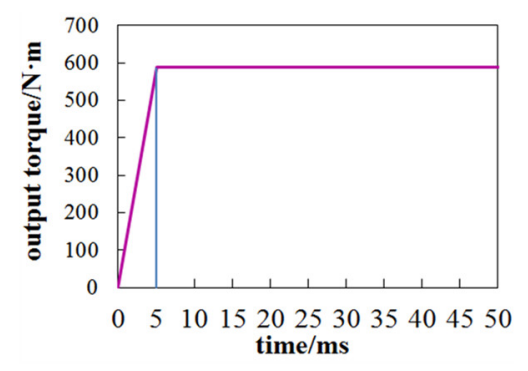

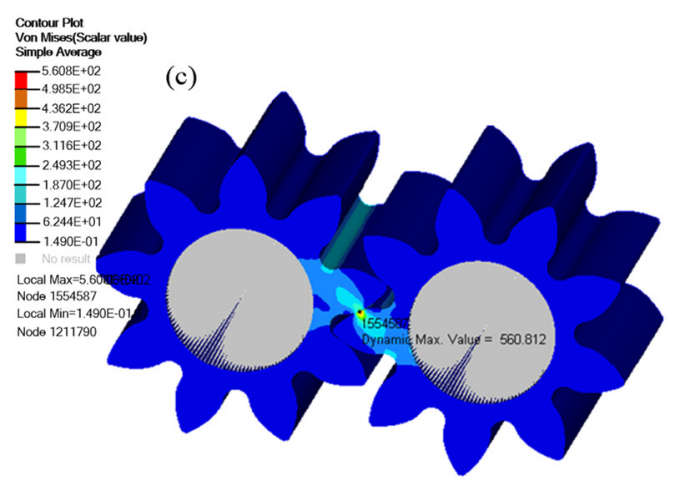

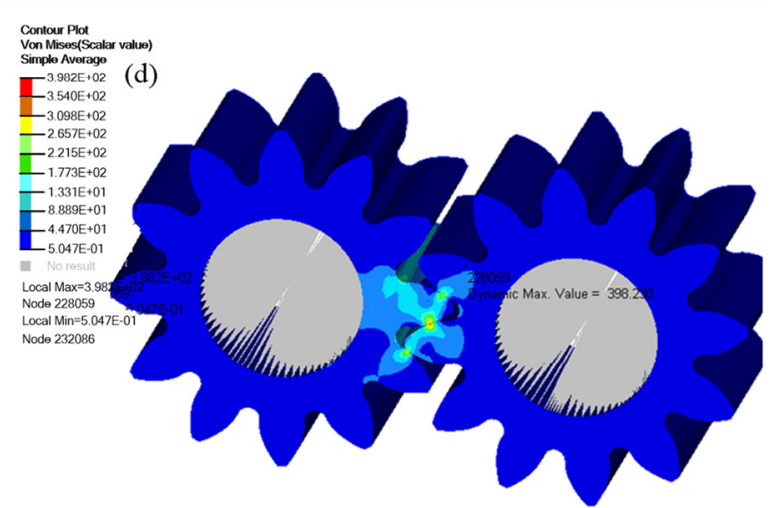

Figure 10. The meshing forces of the gear pump.

The meshing forces of gears at different times were calculated according to the change of the stress value and contact area between gear teeth at different times, as shown in Figure 11. As can be seen from the figure, the meshing force of the 12-tooth gear pump was obviously lower than that of the 9-tooth gear pump, and the maximum meshing force was reduced by about $30 \%$ at a time. 


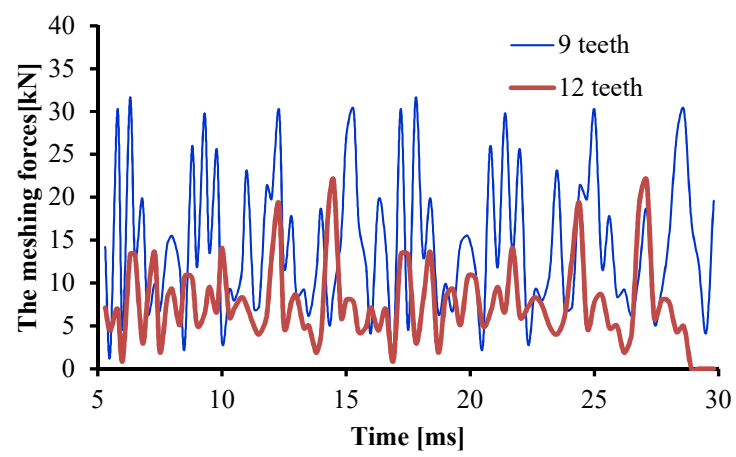

Figure 11. The meshing forces of the gear pump.

\subsubsection{Gear Profile Modification}

From the above analysis, gear profile modification can be used to improve machining accuracy, thereby reducing noise. In this paper, the method of drum shape modification was adopted. Gear manufacturing accuracy can control the influence of gear surface roughness and tooth profile errors on noise. Therefore, the two involute gears of the gear pump were repaired, and the requirements are shown in Figure 12.

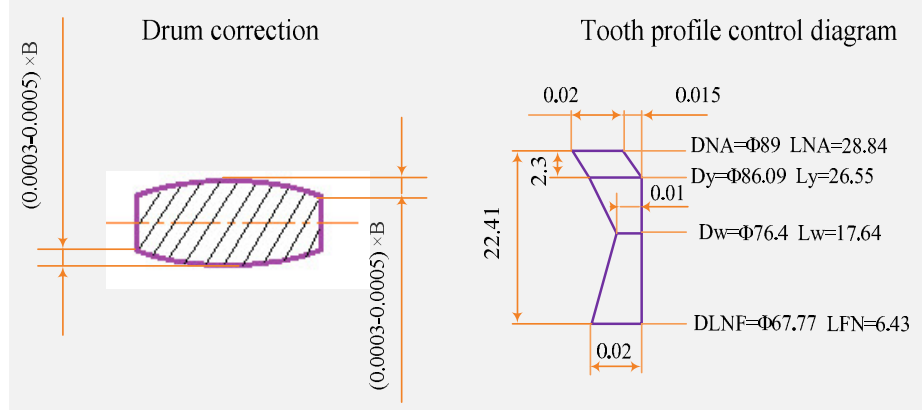

Figure 12. Gear repair requirements.

where DNA is the addendum circle, $\mathrm{D}_{\mathrm{y}}$ is the minimum trim diameter, $\mathrm{D}_{\mathrm{w}}$ is the pitch diameter, and DLNF is the dedendum circle. The tooth profile error is controlled by the left picture, and B is the tooth width. Drum shaped machining can prevent tooth surface contact.

Five gear shafts were repaired with a forming gear grinder, and then the tooth profile was detected with a tooth profile detector. A set of gear shafts was selected; their tooth profile is shown in Figure 13, where $y$-axis represents the radial direction of the gear. The picture on the left is before repair, and that on the right is after repair. Each lattice represents $0.01 \mathrm{~mm}$ in the picture. By measurement, the shape deviation between the tooth profile and the tooth orientation was between $0.01 \sim 0.02 \mathrm{~mm}$, which satisfied the requirement.
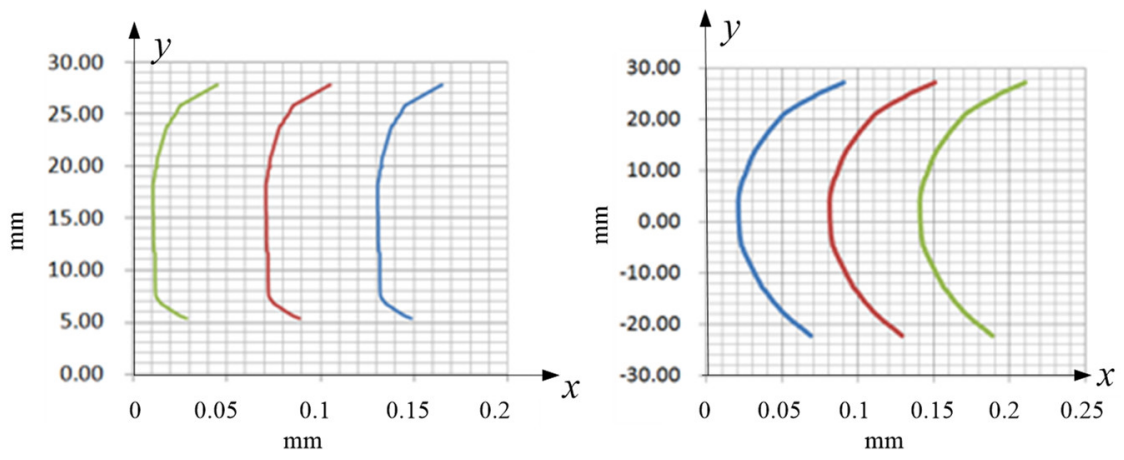

Figure 13. Detection results of the teeth profile modification. 


\subsection{Optimized Gear Pump Test Verification}

The noise value of the optimized gear pump was tested on the test rig, and then the ICA model was used to get the noise signal of the gear pump in the time domain. Finally, the noise test of the wheel loader equipped with the optimized gear pump was carried out to verify the optimization effect of the improved gear pump. Table 3 shows a noise values comparison of the gear pump before and after optimization.

Table 3. Noise values comparison of the gear pump before and after optimization.

\begin{tabular}{cccc}
\hline Symbol & Original Pump dB (A) & Optimized Pump dB (A) & Reduction Value dB (A) \\
\hline The mixed noise value & 100.6 & 95.9 & 4.7 \\
The gear pump noise & 87.6 & 85.9 & 1.7 \\
The driver's position noise & 81.5 & 79.3 & 2.2 \\
The external radiation noise & 110.3 & 109.3 & 1 \\
\hline
\end{tabular}

From the table, the sound power radiation value of the optimized gear pump obtained on the test rig was $1.7 \mathrm{~dB}(\mathrm{~A})$, lower than that of the original one. The external radiation noise was reduced by $1 \mathrm{~dB}(\mathrm{~A})$, and the driver's position noise was reduced by $2.2 \mathrm{~dB}(\mathrm{~A})$ through an external radiant noise test. Combined with Table 2, the driver's position noise value of the optimized pump was less than the $\mathrm{CE}$ authentication values $(80 \mathrm{~dB}(\mathrm{~A}))$, but the external radiation noise value was greater than the $\mathrm{CE}$ authentication values $(107 \mathrm{~dB}(\mathrm{~A}))$. Therefore, in the next stage, the muffler structure of the engine will be redesigned to reduce the external radiation noise.

\section{Conclusions}

In this paper, noise measurement and the structure optimization of a gear pump were carried out in order to reduce the noise value of gear pumps of wheel loaders. The noise test rig was built to reduce the influence of noise from other parts on the noise of the gear pump. The ICA model was established to separate gear pump noise from mixed noise. By increasing the teeth number of the gear pump, the flow pulsation of the gear pump under the rated condition was reduced by $5.7 \%$. The meshing force of 12 teeth was obviously lower than that of 9 teeth and reduced by about $30 \%$ by simulation analysis. Finally, the noise test verified the effectiveness of the noise reduction method by increasing the number of gear teeth and profile modification. The test results showed that the noise value of the gear pump was reduced by $1.7 \mathrm{~dB}(\mathrm{~A})$ after optimization, the external radiation noise was reduced by $1 \mathrm{~dB}(\mathrm{~A})$, and the driver's position noise was reduced by $2.2 \mathrm{~dB}(\mathrm{~A})$. The noise reduction theory can be extended to other construction machinery fields.

Author Contributions: J.Z. (Jianchuan Zhang) and J.Z. (Jun Zhou) conceived the original idea for the study and promoted the survey considering all-round. Q.Z. performed the experiments; and P.H. analyzed the data and writing of papers; F.C. conceived and designed the experiments; L.X. and C.L. made a partial revision of the paper. All authors approved the final manuscript.

Funding: This research was funded by the Key R \& D project of Shandong Province, grant number 2017GGX30141 and 2018CXGC0601, and the postdoctoral fund of Shandong Lingong Construction Machinery Co., Ltd.

Conflicts of Interest: The authors declare no conflict of interest.

\section{References}

1. Shen, H.; Li, Z.; Qi, L.; Qiao, L. A method for gear fatigue life prediction considering the internal flow field of the gear pump. Mech. Syst. Signal Process. 2016, 99, 921-929. [CrossRef]

2. Wang, S.; Du, S. External gear pump model and simulation. Appl. Mech. Mater. 2011, 127, 228-232. [CrossRef]

3. Li, X.; Song, Z.; Wang, T.; Zheng, Y.; Ning, X. Health impacts of construction noise on workers: A quantitative assessment model based on exposure measurement. J. Clean. Prod. 2016, 135, 721-731. [CrossRef]

4. Bilski, B. Exposure to audible and infrasonic noise by modern agricultural tractors operators. Appl. Ergon. 2013, 44, 210-214. [CrossRef] [PubMed] 
5. Patrick, H.; Ruedi, W. Monetization of health damages from road noise with implications for monetizing health impacts in life cycle assessment. J. Clean. Prod. 2005, 13, 1235-1245.

6. Rodionov, L.; Rekadze, P. Experimental vibroacoustic research of a gear pump made of different materials. Procedia Eng. 2017, 176, 636-644. [CrossRef]

7. Fiebig, W.; Korzyb, M. Vibration and dynamic loads in external gear pumps. Arch. Civ. Mech. Eng. 2015, 15, 680-688. [CrossRef]

8. Mucchi, E.; Rivola, A.; Dalpiaz, G. Modelling dynamic behaviour and noise generation in gear pumps: Procedure and validation. Appl. Acoust. 2014, 77, 99-111. [CrossRef]

9. Zhao, X.; Vacca, A. Analysis of continuous-contact helical gear pumps through numerical modeling and experimental validation. Mech. Syst. Signal Process. 2018, 109, 352-378. [CrossRef]

10. Ye, S.G.; Zhang, J.H.; Xu, B. Noise reduction of an axial piston pump by valve plate optimization. Chin. J. Mech. Eng. 2018, 31, 2-16. [CrossRef]

11. Zhang, J.; Xia, S.; Ye, S.; Xu, B.; Song, W.; Zhu, S.; Tang, H.; Xiang, J. Experimental investigation on the noise reduction of an axial piston pump using free-layer damping material treatment. Appl. Acoust. 2018, 139, 1-7. [CrossRef]

12. Bell, A.J.; Sejnowski, T.J. An Information-Maximization Approach to Blind Separation and Blind Deconvolution; Unsupervised Learning; Bradford Company: Bethesda, MD, USA, 1999; pp. 1129-1159.

13. Umeyama, S. Blind deconvolution of blurred images by use of ICA. Electron. Commun. Jpn. 2010, 84, 1-9. [CrossRef]

14. Kamathe, R.S.; Joshi, K.R. A novel method based on independent component analysis for brain MR image tissue classification into CSF, WM and GM for atrophy detection in Alzheimer's disease. Biomed. Signal Process. Control 2018, 40, 41-48. [CrossRef]

15. Madhow, U. Blind adaptive interference suppression for direct-sequence CDMA. Proc. IEEE 1998, 86, 2049-2069. [CrossRef]

16. Back, D.; Weigend, A.S. A first application of independent component analysis to extracting structure from stock returns. Int. J. Neural Syst. 1997, 8, 473-484. [CrossRef] [PubMed]

17. Kuo, S.C.; Lin, C.J.; Liao, J.R. 3D reconstruction and face recognition using kernel-based ICA and neural networks. Expert Syst. Appl. 2011, 38, 5406-5415. [CrossRef]

18. Wang, S.; Sakurai, H.; Kasarekar, A. The optimal design in external gear pumps and motors. Ieee/Asme Trans. Mechatron. 2011, 16, 945-952. [CrossRef]

19. Wang, J.W.; Zhang, H.J.; Huang, Y. Hydraulic and Pneumatic Transmission; Machinery Industry Press: Beijing, China, 2012.

20. Pang, J.; Chen, G.; He, H. Automotive Noise and Vibration; Beijing Institute of Technology Press: Beijing, China, 2006.

21. GB/T 3767-2016. Acoustics-Determination of Sound Power Levels of Noise Sources Using Sound Pressure -Engineering Method in an Essentially Free Field over a Reflecting Plane; Beijing Institute of Technology Press: Beijing, China, 2016.

(c) 2019 by the authors. Licensee MDPI, Basel, Switzerland. This article is an open access article distributed under the terms and conditions of the Creative Commons Attribution (CC BY) license (http:/ / creativecommons.org/licenses/by/4.0/). 